\title{
Fougeret de Monbron: un cosmopolita cínico en mitad de la Ilustración
}

\section{(Fougeret de Monbron: a cinical cosmopolitan)}

\author{
Julio SeoAne Pinilla
}

Recibido: 3 de junio de 2011

Aceptado: 22 de septiembre de 2011

\section{Resumen}

El presente artículo trata de recuperar, a través de la obra El cosmopolita de Fougeret de Monbron, un cosmopolitismo ilustrado de talante cínico. Un cosmopolitismo menos preocupado por el concierto de las naciones y más centrado en el viaje, en el derecho a curiosear y construirse en la atención a aquellos que son diferentes a nosotros a los que muchas veces no comprendemos, pero que, por el hecho de que constituyen el lugar del viaje, son fundamentales para configurar nuestra propia identidad.

Palabras clave: Fougeret de Monbron, Cosmopolitismo, Ilustración, Identidad, Parodia.

\begin{abstract}
From the reading of Fougeret de Monbron's El Cosmopolite I have tried to recover a cinical cosmopolitism which has nothing to do with our classic cosmopolitism -the one we harvest from the Enlightenment and his stoic pitch. With this cinical attitude we can gain a different view in order to consider our global world because we are encouraged to forget the cosmopolitism as a way to manage in the "concert of nations" and to opt for a cosmopolitism focused in the configuration of identity.
\end{abstract}

Keywords: Fougeret de Monbron, Cosmopolitism, Enlightenment, Identity, Parody. 


\section{El Cosmopolita de Fougeret de Monbron}

En 1750 se publicó, a expensas de su autor, Louis-Charles Fougeret de Monbron, El cosmopolita o el ciudadano del mundo. Fue este un librito que tuvo cierta audiencia en su día y a tenor de lo que avanzan los pocos exegetas de Fougeret de Monbron, ejerció notable influencia, siquiera bien ocultada, en autores como Diderot o Voltaire, que entusiasmó a Lessing y sedujo a Byron ${ }^{1}$. Como fuere, lo cierto es que los tiempos se desentendieron de El cosmopolita y cayó en el olvido más apartado del que a veces ha sido recuperado momentáneamente por alguna mención culta cuando se trata de dar cuenta de la historia del cosmopolitismo.

Fougeret de Monbron compuso este libro justo al salir de su primera estancia en la cárcel a partir de los recuerdos de una serie de viajes que realizó entre 1742 y 1748. A partir de esos recuerdos; es importante subrayarlo pues no es "un libro de viajes ni una autobiografía, ni un panfleto político o una sucesión de historias galantes"(Trousson 1971, p. 13), sino una suerte de reflexiones cosidas una tras otras que no serán ni profundas, ni sesudas, ni siquiera ordenadas, sino tan sólo pensamientos con los que el mismo Fougeret de Monbron se presenta "al vuelo" de sus viajes y entre los que se enhebran una serie de afirmaciones, que nunca pretender ser definitivas, sobre el carácter de los habitantes de este mundo.

El primer destino de sus viajes es Inglaterra, a donde viaja atacado por un sentimiento de anglomanía muy común en la Francia de su tiempo que tenía en la política inglesa un modelo envidiado. Allí quiere descubrir al hombre de Diógenes, al verdadero hombre-filósofo ajeno al mundo y entregado únicamente a lo que su corazón e intelecto le dicten como apropiado. Al hombre libre que no depende ni de la opinión de los demás ni de los prejuicios, costumbres o morales al uso. Y aquí, nada más comenzar su periplo, aparece lo que va a ser recurrente en todos sus viajes: no encuentra lo que busca y rehace su petate para marchar convencido de que en todos los sitios cuecen habas. Efectivamente, la desilusión unida al hecho de que su dinero se había agotado le llevan a regresar a Francia y allí, a poco de descansar unas semanas, se nos confiesa como un hombre inquieto que no necesita sino lanzar una pluma al viento para saber la dirección de su próxima partida sin que se cuide de su destino pues "su patria es el mundo" 2 .

\footnotetext{
${ }^{1}$ El interés - escaso ciertamente- en Fougeret de Monbron se ha limitado al análisis de la influencia de Fougeret en otros autores como si la única justificación de leerle fuera señalar los débitos del Cándido de Voltaire con Fougeret de Monbron (Morize 1913, Broome 1960a) o que Byron lo recuerda en la redacción de los dos primeros cantos de Las peregrinaciones de Childe Harold (Broome 1960b) o cómo se inspiró en él Diderot para componer su Sobrino de Rameau. No puedo estar más en desacuerdo con ello pues estoy convencido de que esta obrita merece ser leída no por lo que pudo influir en algunos autores de primera línea, sino porque hoy nos aporta interesantes perspectivas para considerar nuestro propio mundo.

2 "Apenas me restablecí tiré una pluma al viento para saber qué camino tomaría; pues me había formado el proyecto, antes de volver a ver a la feliz Albión, de recorrer la mayor parte de Europa. La
} 
Su siguiente viaje es a Turquía y luego a Italia la cual recorre haciendo numerosas observaciones sobre la Iglesia, los comportamientos beatos y lo que hoy llamaríamos los católicos no practicantes, quienes aparecen a lo largo de toda su obrita como el culmen de la hipocresía. Son estas observaciones, como dije, pequeñas reflexiones sobre lo que ve que no pretenden sentar cátedra y que, además, aparecen siempre acompañadas de su confesión de ignorancia, de su saberse muy poca cosa (al igual que considera al resto del género humano) para pretender decir más que su parecer momentáneo; son realmente pequeñas anotaciones que no están hiladas, que no forman un sistema sobre la naturaleza humana y que se presentan de un modo desordenado, según le toca vivirlas ${ }^{3}$. En este tenor sus siguientes viajes por Prusia, las Provincias Unidas, España y Portugal serán una continua observación sobre la hipocresía de la religión y sus beatos no a través de dictámenes sentenciosos, sino mediante la parodia, la burla -incluso de sí mismo-y el humor del sinsentido.

A Inglaterra regresará en el último viaje relatado en El cosmopolita ${ }^{4}$ aunque esta vez lo hará con algo más de escepticismo sobre la excelencia de los ingleses a quienes, con todo, no les niega que tienen el único sistema político en el que se puede ser libre. Tras reconocer que la excelencia política no va seguida de la altura moral y humana, Fougeret de Monbron retornará a Francia donde se verá inmerso en un proceso judicial kafkiano a razón del cual resultará condenado al destierro, que aceptará de mil amores pues su casa está en cualquier lugar a donde el azar le llevare.

\section{El misántropo Fougeret de Monbron}

Aun con cierto éxito literario, de Fougeret de Monbron no se sabe mucho5. Y lo poco que se sabe (alimentado casi siempre a base de anécdotas que de él se cuentan) reza más o menos como sigue: es un misántropo, sin sentimientos, un animal salvaje sin ningún asomo de humanidad ni simpatía con el género humano. Así lo

suerte me llevó a Italia" (Fougeret de Monbron 1750, p. 32). Esta frase es la esencia de todo el libro de Fougeret: no hay más razón para ir de un sitio a otro que la que el azar depare. Tomar de tal modo el viaje, que al cabo es el fundamento de la vida que El cosmopolita nos relata, es lo que va a conducir mi interpretación: no es la misantropía lo que debe presidir nuestro acercamiento a Monbron, sino el hecho de que la vida no sea más que lanzar "una pluma al viento".

3 "Repetiré aquí, para que no sea olvidado, que, no queriendo ser ni periodista, ni componedor de viajes, no me pararía nunca para hacer el mapa de los diferentes lugares por donde he pasado, ni para contar las morales y las costumbres de los pueblos que he frecuentado. Ya hay demasiadas obras fastidiosas de esta especie en el mundo y no vale la pena que aumente su número con imitaciones o repeticiones. El único fin que me propongo es plasmar en el papel las reflexiones que hice en mis viajes tal como el azar y la ocasión me las sugirieron" (Fougeret de Monbron 1750, p. 33).

${ }^{4}$ Que no el último de su vida pues en el destierro que le llegará tras el juicio con el que termina $E l$ cosmopolita, dirigirá sus pasos hacia Rusia para volver a nuevo a Francia y confinarse en su pueblo natal donde morirá si no de aburrimiento, sí tremendamente aburrido.

5 La vida y obra del mismo Monbron es bien desconocida. Para salvar tal desconocimiento el mejor estudio se puede encontrar en Broome (1963). 
cuenta Diderot en una cita que por ser las más larga sobre nuestro autor ha acabado definiéndole en todos los estudios que de él se han realizado: "Estaba en la Ópera entre el abad de Canaye que ya conocéis y un cierto Montaron, autor de algunos folletos en los que se halla mucho hiel y poco, muy poco, talento. Acababa de escuchar una emocionante pieza patética con cuyas palabras y música me había entusiasmado [...] embriagado por la emoción cogí del brazo a mi vecino Montaron y le dije: - Convendréis, señor, que esto es bello. El hombre con la tez amarilla y las cejas frondosas y fruncidas, con la vista feroz y cubierta me respondió: - No siento tal. - ¿No lo sentís así? - No, tengo el corazón de piedra ... Me estremecí, me alejé de ese tigre con dos patas..." (Diderot 1951, pp. 1188-1189).

Desde esta cita se uniforman los no muy abundantes estudios sobre Fougeret de Monbron. El corazón de piedra de esta confesión habitualmente se entiende como una declaración expresa de misantropía. No, no es un huraño nuestro autor, tampoco un solitario, es un misántropo, alguien que desprecia a la humanidad, alguien cuyo corazón endurecido es incapaz de sentimiento alguno y, con ello, es ajeno a cualquier sensación moral (realmente a cualquier acercamiento humano). Esto, se suele afirmar, se manifiesta en toda la obra de Fougeret de Monbron, mas con especial claridad en El cosmopolita. Efectivamente, en esta obrita vemos a un viajero sin otra casa que no sea el barco o la silla de punto que utiliza en sus viajes, que no recuerda lazos familiares, que no menciona su pueblo de origen sino para burlarse de él. En esta obrita vemos, también, una continua afirmación de que no hay otra ley en el mundo más que la búsqueda del propio interés, y asistimos a la transformación del ciceroniano patria est ubinque bene [la patria está allí donde esté la felicidad] con el cual se abre el libro, en el desapegado contemni et contemnere [despreciando y despreciado]. Un tigre con dos patas le llamó Diderot no porque rehuyera la humanidad, sino porque la desprecia y ataca (y, presumiendo de corazón encallecido, no siente ninguna cercanía con ella). Este es el fundamento de la misantropía de Fougeret de Monbron.

Pues bien, lo que aquí pretendo mostrar es que no es acertada tal calificación al menos en lo que refiere a El cosmopolita, pues cuando lo leemos dejando de lado la fama de su autor lo que comprobamos en primer lugar es que Monbron viaja solo, por propia cuenta e interés, pero no tarda nunca en hablar con quien ve, en entablar amistades, en alabar a quien considera digno de encomio, en definitiva, nunca está solo y no viaja sino para conversar y aprender de lo que escucha en tales conversaciones. Por otro lado, en lo que toca al hecho de que finaliza su libro con el airado contemni et contemnere, hay que decir que el episodio final relata su kafkiano proceso judicial, su paso por la cárcel y su comprensible enfado con quienes le han condenado simplemente por querer ser un espíritu libre. No es odio a la humanidad lo que se refleja en su grito final, sino, más bien, odio a quienes la gobiernan y le impiden dirigir sus pasos a su antojo. 
Permítaseme dar un pequeño rodeo para mostrar mi desacuerdo con la acusación de misantropía hecha a Fougeret de Monbron. Hace ya tiempo S. Toulmin mostró, en un excelente y clarificador trabajo (Toulmin, 2001), que la idea del cosmopolitismo tuvo un uso que iba mucho más allá de sentirse ciudadano del mundo. Por ser breve diré que su convencimiento hacía referencia al hecho de que desde el XVII el mundo de la reflexión se inclinaba a tomar su objeto de estudio desde una visión atomista que suponía que es cada individuo - cada sujeto de conocimiento si se quiere ser más preciso- el punto central desde el cual se da el visto bueno no sólo al conocimiento, sino a la misma moral y las esperanzas de vida. Cual punto de fuga de la perspectiva sobre la que se representa el mundo, el sujeto del conocimiento funda, en esencia, la relevancia de la existencia del mundo. A partir de tal idea era fácil considerar el comercio entre los hombres como una sociedad fruto del orden establecido entre átomos que no hacían sino perseverar en sí sin tener necesidad de mirar mucho más allá de la propia satisfacción para poder fundar el nuevo mundo. Consideración que, dígase de paso, nos ha llegado hasta hoy casi intacta. Como es sabido, la consecuencia de todo esto era la dificultad de imaginar un modo en como tales mónadas constituían una vida en común - una sociedad - si no era desde el convencimiento de que aquellos átomos, sin necesidad de atender más que a sí mismos, edificaban mecánicamente una vida en común. Quizás sea Mandeville quien mejor presente la manera en como apareció nuestra Modernidad; que los vicios privados traen virtudes públicas es sencillamente proponer la idea de que cada quien no piensa sino sobre su propio bien y que ello (guiado posiblemente por lo que unos años más tarde Adam Smith llamará una "mano invisible" y que más lejanamente se traducirá como "mercado" en unos casos o argucia de la razón en otros) apareja la riqueza de las naciones, su bienestar, su progreso (el orden social, en suma).

Frente a esta ciertamente desalentadora visión donde la vida en común se edificaba sin necesidad de mirar más allá de sí mismo ( $\sin$ contemplar realmente a los demás), según Toulmin en el XVIII se deslizó una sensibilidad estoica que atemperaba y aliviaba el rigor mecanicista; y en esta sensibilidad iba incluida la idea de cosmopolitismo. Esta idea suponía que quizás cada quien no mirara más que a sí, que quizás todo partiera de un sujeto de conocimiento aislado, pero realmente todos teníamos una misma naturaleza que nos hacía iguales y que aparejaba un modo común de estar en el mundo. Este cosmopolitismo de origen estoico supuso, como veremos más adelante, un diferente modo de organización política, pero también supuso el intento y la posibilidad de imaginar un lugar de fundamentación de nuestras relaciones sociales más allá del choque entre átomos. Así, aunque todos estuviéramos de acuerdo en que de hecho no fuéramos sino seres egoístas, podíamos quedar emplazados a buscar un derecho que pudiera reconocernos como algo más de lo que efectivamente éramos. 
En suma, es generalizado, durante toda la formación de nuestra Modernidad, el convencimiento de que la humanidad está hecha de un retorcido tronco del cual es difícil obtener nada y que sería imposible imaginar que nuestro mundo caminara a mejor si no tuviéramos la esperanza de que algún tipo de argucia nos estuviera conduciendo hacia donde ella consideraba mejor sin importarle nuestras siempre corrompidas opiniones. Llámese a tal argucia historia, progreso, mercado o de cualquier otra manera, lo cierto es que aun con todo el mundo diferente que se pueda construir con cada una de tales opciones, en definitiva siempre hemos encontrado una extrema prevención ante posturas como las de Mandeville que conciben las relaciones entre los seres humanos en su facticidad sin querer ir algo más allá de lo efectivamente humano. Puesto que sería descorazonador aceptar tal mundo, el cosmopolitismo venía a posibilitarnos la empresa con la que hemos construido buena parte de nuestro presente: nosotros nos hemos caracterizado por buscar algo que bajo las efectivas relaciones interesadas las diera algún cuerpo y visos de dignidad (algo a partir de lo cual poder imaginar una vida justa). Bien, entre el mundo de Mandeville y el que hemos ido creando con mucho pesar desde el XVIII, Monbron apuesta por el primero; por ello Diderot le declaró misántropo, porque ni se cuidaba de, ni le importaba la humanidad, porque, en realidad, ni siquiera consideraba que existiera tal humanidad y tan sólo se tenía a sí.

Pero no es un misántropo nuestro autor; y si siempre se pone a sí mismo por delante de todo, nunca rechaza el comercio con los demás seres humanos aunque bien es cierto que no adorna a tal comercio con grandes alharacas ni considera que en él se destile la humanidad (o se muestre alguna naturaleza humana o algún derecho o racionalidad). En este sentido su actitud es simplemente la contrapartida a la generalizada "filantropía" de las luces que consideraba que se podían organizar nuestros intereses a partir de alguna pretendida naturaleza humana, racionalidad o progresión histórica que diera cuerpo y fundamento al arreglo fáctico de intereses 6 .

Considerar que quien afirma que "los hombres me eran odiosos" (Fougeret de Monbron 1750, p. 34) o que "soy un ser aislado en medio de los vivientes" (Fougeret de Monbron 1750, p. 38) se sitúa fuera de la humanidad simplemente por tener un carácter arisco, asocial y egoísta es una forma sencilla de no querer escuchar lo que Fougeret de Monbron quiere decir (y quedarse en la anécdota de su carácter), a saber, que no es preciso adjuntar al inicio de nuestra Modernidad ninguna afirmación que nos haga más soportable la crudeza de que tal Modernidad se funda en la acorazada individualidad y libertad del individuo; este, considerado como el punto inicial desde el que construir la realidad, es un ser aislado, un átomo, una mónada, y su comunidad se ha de constituir como una sociedad donde la vida

\footnotetext{
6 Y, como afirma F. Venturi, de ahí viene su valor político (Venturi 1947, p. 171). Más adelante Venturi añade: "En un siglo que es al mismo tiempo entusiasta y calculador, elegante y vulgar, Fougeret es algo valioso con su cosmopolitismo fundado sobre el pesimismo" (Ibid., p. 177).
} 
de tales mónadas sea factible. Y si la Ilustración en buena medida se bañó en un talante estoico que aportaba algo de "humanidad" a la asunción de la naturaleza humana tan atomizada, tal "humanidad" no dejaba de ser, para nuestro autor, un remedo de un Dios que los tiempos comenzaban a dejar de lado.

En este sentido, me da la impresión que un comentarista de su propio tiempo, A. Goudar, dio de mejor manera en el blanco cuando en una reseña que realizó de La Capitale des Gaules, calificó a Fougeret de Monbron no de misántropo sino de "ateo social"7 pues, en definitiva, lo que caracteriza a nuestro autor es su negativa a creer que pueda existir alguna organización social que pudiera considerarse justa o "más" adecuada a la humanidad. O mejor, ateo social lo es por descreer de la existencia de la Humanidad (acreedora de derechos y futuro) más allá de los individuos que cotidiana y azarosamente encontramos. Y, efectivamente, no es misantropía, es descreimiento: no podremos ser nunca como dioses y en verdad somos tan poca cosa que a ninguna ley realmente universal podremos jamás llegar; no somos más que los caracoles o las hierbas que crecen cerca de nuestro tonel y tratar de reunirnos en un orden que gobierne el universo o en una naturaleza humana que nos vincule (más allá del hecho de que somos seres humanos -interesados-) es algo que nos excede con mucho 8 .

\section{EI libertino y su sociedad}

No creer que valgamos mucho y considerar que la independencia es un valor fundamental no significa que se huya de la sociedad con nuestros semejantes. Como he dicho, quien acusa a Fougeret de Monbron de misantropía parece no leer que en El cosmopolita nuestro autor pasa su tiempo viajando, pero que al llegar a su destino lo primero que hace es entablar alguna amistad, hablar con la gente, disfrutar con los demás 9 . Es bien cierto que sus interlocutores más queridos, aquellos con los que realmente forma sociedad (unas veces dichosa, otras desafortunada, pero siempre sociedad), suelen ser prostitutas, exiliados o pícaros, pero porque nuestro autor encuentre a sus semejantes en las orillas de la comunidad política no es razón para acusarle de misantropía, de odio a la posibilidad de construir una ciudad. Por el contrario, esa es la sal del texto de Monbron que con ello se constituye en un texto "pro-

\footnotetext{
7 Citado en Venturi (1947), p. 186.

8 "No es el objetivo de las leyes y de la buena disciplina ni cambiar la obra de la Naturaleza ni refundar nuestros corazones, su intención solamente es la de ayudar a librarnos de nuestras inclinaciones criminales. Nadie es responsable de sus malas raíces, pero sí de sus malas acciones. Lo que oscurece a la sociedad es llevar a cabo el mal y no el secreto deseo de hacerlo" (Fougeret de Monbron 1750, p. 37-38).

${ }^{9}$ Siquiera porque "no se puede estar eternamente entregado a uno mismo; un poco de compañía, buena o mala, ayuda a pasar el tiempo" (Fougeret de Monbron 1750, p. 38).
} 
vocativo capaz de transformar el ciceroniano y anodino Patria est ubicumque est bene en el agresivo lema personal: contemnere et contemni" (Angeli 1974, p. 123).

¿Fougeret de Monbron, un misántropo? En todo caso un misántropo bien curioso pues escribe a otros, a otros se dirige, con otros construye su propia vida... posiblemente sea tan sólo un hombre contradictorio que se ha dado cuenta de que el primer paso puede ser el amor a uno mismo, el propio interés si queremos decirlo así, pero que tal paso inmediatamente genera algún tipo de cariño, de relación donde el corazón se emociona y deja de ser el de un tigre para convertirse simplemente en el de un ser humano que muchas veces ni siquiera sabe quien es hasta que se topa con el relato de su propia vida. De hecho a poco de comenzar a leer El cosmopolita comprobamos que si bien toda aventura comienza con una declaración de independencia y autonomía por parte del autor, en la primera amistad que surge, en el mismo instante que el comercio con la humanidad se establece (y ello ocurre continuamente) aparece un sentimiento de cuidado y vinculación que nos muestra que no son estas las reflexiones de un solitario, sino de alguien que se conoce a sí mismo con los demás.

De quien sí desconfía, de quien sí huye es de aquellos que se relacionan con el poder. Son estos, al cabo, quienes le van a acusar de misantropía, de huir de la sociedad humana, pero es que ante ellos Fougeret de Monbron enarbola continuamente su rechazo, su odio, su contemni et contemnere. Y ello por dos razones. La primera porque suelen entorpecer la independencia que Monbron busca y a menudo dictaminan prohibiciones para hacer y decir aquello de lo que nuestro autor desea disfrutar. La segunda porque ello lo llevan a cabo desde el convencimiento de que tienen la verdad y la posición para establecerla, de que su discurso es ley porque puede hablar "a todos y para todos". Y eso le resulta insoportable a Monbron que siempre desprecia a todo aquel que se las da de sabio (de tener un saber y también reclamar por ello algún tipo de poder) y se burla incluso de sí mismo cuando a veces se le ocurre pontificar sobre algún asunto ${ }^{10}$. Quien enarbola su saber y con él nos desvela alguna verdad ignora (y generalmente de modo interesado) que en definitiva todo nuestro conocimiento no es sino la excusa para hacer alguna cosa (y generalmente de nuestro interés), que no hay verdad inocente $y$, sobre todo, que no hay posibilidad de verdad pues no somos nada, no sabemos nada y por ello lo que decimos nunca puede ser más que un ejemplo de nuestra vida el cual no tiene más valor que retratarnos ${ }^{11}$.

10 "No me avergonzaré en absoluto por confesar que entre tantas cosas hermosas que he visto hay muchas que no he encontrado tales sino sobre la fe de otros y en absoluto desde el testimonio de mis ojos. Pueda esta confesión sincera de mi ignorancia servir de lección a aquellos disertadores indiscretos y charlatanes que tienen el eterno furor de juzgar de lo que no entienden y que, como el marqués de Mascarilla, saben de todo sin haber aprendido de nada. No hay, para desgracia de los oídos delicados, sino demasiados impertinentes de este tipo en el mundo. Lo confieso con vergüenza: a menudo tengo merecido un epíteto parecido" (Fougeret de Monbron 1750, p. 49).

11 Véase en la siguiente cita con qué ironía trata a todo saber que se proclame como tal: “iQué no tenga 
En suma, Fougeret de Monbron tan sólo considera sus viajes como una lectura del libro de la vida y no como una revelación de aquello que unifica todas las vidas, nos expone sus juicios y pronunciamientos, pero lo hace desde sus propios pasos, con los placeres que de ellos se obtienen, con las advertencias que de sus situaciones se extraen, etc. No hay ninguna sentencia, ninguna afirmación imperecedera, ninguna verdad última que establecer porque el viaje es azaroso, las amistades también y la misma vida que se compone entre ambos no deja de ser cambiante y nunca imaginable antes de iniciar la jornada. En este sentido El cosmopolita plantea que el mundo que podemos concebir es mucho más que el mundo que se puede encerrar entre fronteras; el viaje plantea que no hay de-finiciones, que no hay un saber último que pueda quedar establecido sin posibilidad de ser impugnado por el azar que lo lleva de un sitio a otro, que "todo aquí abajo es igualmente ridículo y que la perfección de las cosas no consiste sino en la opinión que de ellas se tiene" (Fougeret de Monbron 1750, p. 24) ${ }^{12}$. Desde aquí el viaje de Fougeret adquiere un cariz cínico que nos muestra otro modo de entender Cosmópolis.

yo el exquisito gusto, el consumado saber y el talento maravilloso para pintar que tienen esos famosos literatos que poseen el secreto único para representarnos bajo las más pomposas imágenes cosas de las que no dominan sino los elementos más rudimentarios merced a media docena de palabras de imitación! Sería sin lugar a dudas una bonita ocasión para pasar por un virtuoso de ocasión. Los términos de alquitrabas, de frisos, de capiteles, de bajorrelieves, los de diseño, de composición, de colorido, de reflejo, distribuidos sabiamente y con economía, elevarían admirablemente una descripción y añadirían mucho al mérito de su autor; pero mi insuficiencia no me permite hacer ensayos parecidos. Me contentaré con decir, sin tomar ese tono sentencioso que no me va en absoluto, que he visto enormes piezas de toda suerte de estilos en los que reconozco no haber apreciado las bellezas sino bien débilmente a falta de ser un iniciado en los misterios de la gente de la profesión" (Fougeret de Monbron 1750, p. 45).

12 No creo que haga falta decir que como cualquiera se puede imaginar, y como acontece en los libros de viaje de la época, El cosmopolita es también un recuento de situaciones que nos recuerdan lo ridícula y "propia de nuestra cultura" que es toda nuestra concepción de la vida humana como la que a continuación se cita en referencia a la diferente música de la que gustan turcos y franceses: "Esos aplausos me dieron pena. No podía concebir que una sinfonía que me destrozaba los oídos y que una voz chillona que salía de la raíz de la nariz pudiera nunca encontrar partidarios; pero iba a tener ocasión para sorprenderme más cuando en otro momento quisimos ofrecer un plato de nuestro oficio a esas mismas gentes: nuestros instrumentos y nuestra voz no fueron aplaudidos sino por estallidos de risa tan escandalosos como humillantes. Me acordé entonces de uno de nuestros refranes que dice que sobre gustos no hay nada escrito. En efecto, el gusto es arbitrario; y es una especie de tiranía pretender someter a los demás a los propios. No es una prueba, en la medida en que hemos adoptado la melodía y la dulzura en nuestra música, que los sonidos agudos y penetrantes no pueden tener su mérito. Todo depende en este mundo de la manera en la que hemos sido enseñados y de la costumbre. Algunos ó́dos pueden verse afectados tan deliciosamente por los ruidos agrios que a nosotros nos desalientan, que les choque la dulzura de los sonidos de los que gustamos. No hay en modo alguno una regla fija en lo que toca al placer y el atractivo" (Fougeret de Monbron 1750, p. 23-24). 


\section{El cosmopolitismo cínico}

La sensibilidad estoica que atemperaba y aliviaba el rigor mecanicista, aquella que incluía en sí la idea de cosmopolitismo, también suponía un nuevo orden político. Realmente es esto lo que suponía en primer lugar el cosmopolitismo. Por seguir la idea de Toulmin anteriormente presentada, hay que decir que esa misma naturaleza que nos hacía iguales y que aparejaba un modo común de estar en el mundo llevaba a que, en el orden de la organización política, todo Estado (bajo el cual los hombres desarrollaban su vida) daba forma a una misma naturaleza, la naturaleza humana y, a su vez, ello posibilitaba que todos nos pudiéramos reconocer en un Estado, el nuevo Estado-nación que entonces comenzaba a aparecer. De tal modo (a) la ciudad se hacía coextensa con la naturaleza y, con ello, los derechos de los humanos lo eran también del ciudadano y (b) este fue el camino por el cual el cosmopolitismo se constituyó en la base de la estabilidad de los nacientes Estados-nación y del orden internacional que tales Estados comenzaban a constituir (al cabo la ley del Estado no debía sino reflejar la ley de la naturaleza humana) ${ }^{13}$.

No debemos olvidar esta vinculación del ideal cosmopolita con la estabilidad del Estado-nación y que tal ideal, en última instancia, es la reclamación de una naturaleza común a todos los hombres que les hace acreedores de una ley común, una ley que puede tener sus variaciones nacionales, pero que en esencia es compartida por todos los seres humanos y, por ello, puede generar un concierto de naciones. Incluso hoy mismo, cuando nosotros utilizamos la noción de cosmopolitismo lo hacemos convencidos de que somos ciudadanos del mundo porque podemos sentir como propia la ley de la humanidad y, con ello, extender los límites de la ciudad en la que vivimos hasta donde tal humanidad alcance. O dicho de otro modo: nuestra ciudad es aquella en la cual pueden habitar los seres humanos. Humanidad y ciudad se hacen coextensas y el Derecho de esta es el Derecho -los Derechos- de la Humanidad misma. Esta es la esencia del nuestro cosmopolitismo y por ello, aunque no dejamos de reconocer las diferencias que, por ejemplo, marcan el idioma y las costumbres, las tratamos como accidentes que acceden a una misma Humanidad gobernada por un mismo cuerpo de Derechos.

\footnotetext{
13 Por terminar con la tesis de Toulmin: si Cosmópolis es la idea de que el orden del Cosmos se debe reflejar en la ciudad de los hombres, esta, de tal modo, puede obtener un fundamento tan firme y seguro como aquel. A partir de aquí el cosmopolita es un ciudadano global no en el sentido del viajero montañista que viaja y mira, sino en el de quien sabe que hay un orden y él pertenece a tal orden. Pero, tanto como un ciudadano del mundo, también es, el cosmopolita, el ciudadano de un estado nación, donde el rey, como el sol, gobierna todo el movimiento de los elementos sociales: bien podemos ser diferentes y diversos (con distintas energías y capacidades e intereses), pero existe una naturaleza que a todos nos une y vincula, que nos hace iguales y libres en la medida en que nos apercibimos $-\mathrm{y}$ por ende aceptamos- del orden justo y natural. El lugar en el que vivimos no es sólo el sitio en el que estamos, sino el puesto del cosmos en el que nos corresponde vivir (y somos conscientes de ello).
} 
Hoy que el Estado-nación parece quebrar y que el ideal cosmopolita lleva aparejada una globalización uniformadora constantemente criticada, creo que merece la pena repensar la cuestión del cosmopolitismo de nueva manera. Y posiblemente Fougeret de Monbron nos pudiera ayudar a ello puesto que su cosmopolitismo es más bien un modo de ser viajero, de lanzarse al viaje, con lo cual termina remitiéndose a los modos en como configuramos nuestra identidad antes que a la manera que tenemos de organizar nuestra vida con los demás. Trataré de mostrar como ello nos puede ser de alguna ayuda hoy.

No deja de ser revelador que en todas las historias sobre el tema del cosmopolitismo se mencione de modo muy rápido que es Diógenes quien propone la noción de "ciudadano del mundo", lo mismo acontece con la mención de $E l$ cosmopolita que cuando aparece no deja de ser una cita culta que con obligada renuencia se contempla para pasar con rapidez a dar cuenta del que es el único y verdadero cosmopolitismo ${ }^{14}$. Como sea, desde Diógenes a Fougeret de Monbron podemos trazar una línea a partir de la que dibujar un cosmopolitsimo de cariz cínico que, al igual que el de raíz estoica -el nuestro-, también parte de la idea de que todos somos iguales, aunque considera que ello es así no porque tengamos algún Derecho común, sino porque somos muy poca cosa, tan poca cosa que no podemos imaginarnos ni en un Estado estable ni en un lugar sujeto a derechos claros y distintos, sino tan sólo en un terreno donde poder caminar según nuestra pequeñez desee. Lanzamos una pluma al viento y el azar decide la dirección de nuestros pasos -y con ello nuestra misma patria- quizás porque ni siquiera de nuestra decisión somos dueños; pero tal decisión debe ser seguida porque aunque hayamos puesto poca de nuestra voluntad en ello, el camino indicado constituye todo lo que vamos a poder ser. Ya no una política común, sino un modo común de hacer la propia vida es lo que constituye el cosmopolitismo cínico cuyo mejor representante es Fougeret de Monbron y que, en último término, se puede retrotraer hasta ese hombre que en un tonel tan sólo pedía que se le dejara hacer su vida.

Realmente a poco que pensemos nos daremos cuenta de que nuestro cosmopolitismo ha acabado siendo el que no precisa salir de casa para sentir que el mundo es nuestra casa y, con ello, niega que sean fundamentales las diferencias que podría encontrar más allá de la propia puerta. Aun antes de salir, sin necesidad siquiera de abrir la puerta, ya sabemos como deben ser quienes viven allende nuestro barrio. Por muy allende que vivan. Fundamentalmente todas las casas son como la nuestra y tan sólo habrá pequeñas variaciones de decoración que no cambiarán en mucho la estructura básica del hogar al que estamos acostumbrados. Pero viajar realmente, o al menos así se lo parecía a Fougeret de Monbron, es desplazarse de lugar y mirar.

14 Una útil, aunque muy rápida, contraposición entre el cosmopolitismo estoico y cínico se puede encontrar en el revelador artículo de Lettevall (2008). La idea generalizada es que Fougeret de Monbron no es un auténtico cosmopolita, sino un viajero curioso que equivocó el título de su libro. 
Y este mirar que se desplaza no puede llegar a constatar cómo son realmente las cosas (ni antes ni tampoco después de mirarlas); de hecho no puede constatar que nada sea realmente y para siempre, sino que, por el contrario tan sólo dispone ante nosotros una película cambiante que nos dice que somos una parte (¿cambiante?) de tal película.

Viajar y mirar, no para fijar las cosas sino para verlas cuando se explican y se muestran, es lo que constituye la esencia del curioso que es Fougeret de Monbron pues, si las cosas, las personas y las situaciones aparecen en el viaje, resulta que son en tanto son parte del mismo y tan sólo cobrarán sentido en el relato de tal viaje. Nuestro viajero no puede creer en ninguna definición capaz de estatizar lo real, no puede creer que la razón humana (viajera y contingente más que poderosa y divina) sea capaz de decir la última palabra acerca de nada; por ello tan sólo tenemos el relato, el momento cuando las cosas se explican. Y los momentos son fugaces, son adecuados al lugar y contexto; no casan bien en definitiva, con la esperanza estoica en una ley que a todos nos organice: viajar es necesario para conocerse y conocer nuestra vida con los demás. Por ello no hay una ciudadanía anterior al viaje. Decididamente no hay nada anterior al viaje del curioso, pero tampoco lo hay más allá del viaje; ni ley, ni ciudad, ni siquiera una identidad a la que adscribir algún tipo de derechos. Este es el convencimiento del ateo social que es Fougerent de Monbron: nada hay más allá de nuestros pasos.

Frente a Cosmópolis, el único derecho del cosmopolita cínico resulta aquel que la curiosidad reivindica para reclamar la inquietud y el deseo de salir de viaje al menor descuido. Es más bien el "derecho del curioso" el que Fougeret reclama, el deseo de poder pasear y vivir en todas las ciudades; desear estar en todos partes y no sentir ninguna como propia es saberse dueño tan sólo del propio azar que nos lleva de un lugar a otro. Con ello para el viajero cínico las fronteras son fluctuantes, no quedan definidas sino por el mapa de su caminar ${ }^{15}$; no es que existan países y el buen cosmopolita pueda vivir en todos, atender a todos, sentir cercanos a todos porque la humanidad entera tenga un poso común, es más bien, que las fronteras son permeables, que no definen ni legitiman nada, que están ahí como parte del saber humano, de su voluntad constructiva si se quiere, pero puesto que tal saber y voluntad es siempre risible y contingente, las fronteras, las naciones, los cambios de idioma y costumbre quedan, también, impugnadas por nuestro propio caminar16.

15 "El escaso placer que probé en mi estancia en Lisboa junto con el miedo continuo que tenía de caer bajo la garra de los señores del Santo Oficio, me hizo tomar la decisión de partir lo antes que pudiera. No tardé en encontrar la ocasión. Una flota inglesa estaba a punto de izar velas para la Gran Bretaña y creí que no podía hacer nada mejor que aprovecharlo. Comuniqué mi deseo al Sr. De Chavigny, embajador de Francia. Me preguntó si había olvidado que entonces estábamos en guerra con Inglaterra. Respondí que no, pero que yo era un habitante del mundo y que guardaba una estricta neutralidad entre las potencias beligerantes" (Fougeret de Monbron 1750, p. 126).

16 "Mi retirada es tanto más apacible cuanto que yo me encuentro bien en cualquier sitio menos en prisión. Todos los países me son iguales siempre que pueda gustar en libertad de la claridad del cielo y 
Como fuere, lo cierto es que el cosmopolita cínico debe referir a un mundo que va más allá del concierto entre naciones, que expande su cualidad cosmopolita no en las condiciones de posibilidad de viajar (en el hecho, por ejemplo, de que Francia e Inglaterra deban estar en paz y constituyan un orden globalizado para poder ir de un país a otro), sino en el deseo interior de ponerse de viaje (en aquello que nos debe llevar de un país a otro sin importarnos el estado de sus relaciones diplomáticas o la globalización del mundo: viajamos porque sin viaje no somos) porque, en definitiva, no es que yo pueda estar con los demás, es que, al final, soy -literalmentelos demás (y "yo mismo" no soy nada).

\section{El cosmopolitismo interior}

Poder viajar sin que ningún viaje sea nunca el mismo viaje y, en último término, tan sólo reclamar el derecho a poder buscarse la vida independientemente de las fronteras que se atraviesen, ese es el derecho del viajero que supone una antropología del curioso de la que ahora quiero decir algo. Y para ello deseo presentar una de las características principales de la escritura de Fougeret de Monbron. Me refiero a su humor paródico.

Como parodia de La Henriada de Voltaire publica La Henriada travestida, como parodia de las obras de Crebillon, sin ir más lejos de El Sofá, publica El canapé color de fuego, la misma Margot la remendona es parodia de la habitual novela erótica rococó... No hay una sola línea que Fougeret escriba que no tenga como base la parodia, el cínico sarcasmo a veces o el continuo propósito satírico (Michel 2003, p. 61); pero no el odio a la humanidad, tan sólo el deseo de mirarla, de reirse de ella, de poner en solfa sus hipocresías y llamar la atención sobre lo ridícula que es. Ello no es misantropía, no es desprecio de lo humano, es simplemente reconocer lo pequeños y risibles que somos y reconocerlo cuando precisamente se vive con nosotros y cuando, como le ocurre a Fougeret de Monbron, quien vive con nosotros se siente uno de nosotros. No, no somos despreciables, simplemente somos pequeños y cuando nos damos ínfulas de seres celestiales movemos a risa. Fougeret se mofa de nuestra apostura (como se ríe de sí mismo antes que de nadie17), mas en tal

que pueda mantener convenientemente a mi persona hasta el fin de sus días. Señor absoluto de mi voluntad y soberano independiente, cambiando de lugar, de costumbres, de clima a mi capricho, tengo todo y no necesito de nada. Hoy estoy en Londres, quizás dentro de seis meses estaré en Moscú, en San Petesburgo, en fin ¿qué se yo? No sería un milagro que fuera un día a Ispahán o a Pekín” (Fougeret de Monbron 1750, p. 136).

17 "Confieso pues, de buena fe, que de todas las criaturas vivientes soy al que más amo, sin que por ello me estime en ventaja. La necesidad inevitable en la que me encuentro de vivir conmigo mismo me obliga a ser indulgente y a soportar mis debilidades y como nada me ata así de estrechamente con el género humano, no se debe encontrar extraño que no tenga la misma complacencia con las ajenas" (Fougeret de Monbron 1750, p. 36) 
burla no hay desprecio, sencillamente es una llamada de atención sobre nuestros pies de barro. Por eso el cinismo de Monbron es algo más que el cinismo clásico. Reconocer que somos poca cosa es reconocer que cambiamos, que nos contradecimos, que no seguimos un orden para contar(nos) ${ }^{18}$, que nos hacemos de distinta manera según con quien estemos. Las fronteras que no se reconocen no son únicamente las fronteras de las naciones, sino también las que hacen referencia a aquellas fronteras con las que se define la propia identidad.

Somos fluctuantes y ello no solamente se manifiesta en el hecho de que no alcanzamos nunca una identidad fija y estable, sino en que por ser tan poca cosa ni siquiera lo que somos se libra de la contradicción. Ni las mismas reglas de la lógica son sostenibles por alguien que ha hecho del humor (y el ridículo) su bandera. La contradicción es la base de la vida de los hombres y en ella se fundan la mitad de las burlas que en boca de Fougeret se escuchan. Católicos que se declaran no practicantes, beatas a las que en secreto el cuerpo las domina, prostitutas que son tiernas y sensibles... son protagonistas que aparecen en El cosmopolita y con los que se mueve a risa al lector. Pero en esa risa aprendemos no tanto la crítica de lo que no debe ser, cuanto la pequeñez de lo que inevitablemente somos (lo cual deja en ridículo cualquier declaración elevada, sea esta religiosa, moral o legal $\left.{ }^{19}\right)$. Quién sabe si Fougeret no se consideró a sí mismo un misántropo por mucho que su Cosmopolita lo negara continuamente; quién sabe si cuando confesaba "de buena fe, que de todas las criaturas vivientes soy al que más amo" (Fougeret de Monbron 1750, p. 36) se olvidaba de que continuamente se burla de sí mismo y no le duelen prendas en calificarse de tacaño, cobarde o ridículo; quién sabe si el mismo Fougeret no pasa por alto que no pocas veces es sentimental y tierno 20 ; y es que parece que nuestro autor es una persona tan normal como cualquiera. Hasta contradictorio es. No olvidemos que El cosmopolita comienza con la confesión de que su autor no va a establecer reflexiones ordenadas, coherentes, bien explicadas, sino que simplemente se limitará a lanzar sus pensamientos al vuelo (lanzarse a sí mismo al mundo con cualquier oportunidad); y posiblemente en la mochila de su identidad lleve la humana contradicción como quien lleva la cantimplora y algo de ropa de

\footnotetext{
${ }^{18}$ La única regla es que no hay regla ninguna: "os advierto que mi testarudo espíritu no conoce regla ninguna y que semejante a la ardilla, salta de rama en rama sin quedarse en ninguna. Mi espíritu voluntario no conoce reglas" (Fougeret de Monbron 1750, p. 51); "Es bueno por lo tanto que les advierta de que mi imaginación vagabunda no sabría compadecerse con el orden metódico" (Ibid., p. 13).

19 "Nunca consentiré en escuchar a un Original que me aburre ni en estimar a un Bellaco al que menosprecio, y todavía menos en prodigar mis alabanzas a algún Despreciable. Esto no es porque me crea de mayor valor que el resto de los humanos: no quiera Dios que éste sea mi pensamiento. Al contrario, confieso con la mejor fe del mundo que precisamente no valgo nada" (Fougeret de Monbron 1750, p. 36).

20 “Al hilo de estas memorias, Fougeret de Monbron se revela como un ser complejo, más vulnerable que realmente arisco [...] en fin, un Monbron tierno" (Lagille 2010, pp. IX-X).
} 
abrigo. Ello es lo que permite a Fougeret cultivar una imagen de hombre con el corazón agrio al tiempo que gusta de estar, escuchar y atender a quienes se acercan a él (y lo que es más importante: a aquellos a los que él se acerca).

Bien, si la identidad es de fronteras fluctuantes y nunca de-finida, si hasta puede ser contradictoria y nos mueve a risa la actitud que concluye en "así soy" o "así es la humanidad", resulta que lo único que nos queda es el viaje, aquello que aparece en el primer párrafo de El cosmopolita, aquello que da sentido al recuento de la vida de Fougeret de Monbron. El viaje es el único fundamento que podemos poner a nuestra humanidad (a nuestra naturaleza humana); es la posibilidad de caminar nuestros propios pasos azarosos para dar lugar al relato en el cual se va a contar la identidad. Una identidad que no precisa ser idéntica $-\mathrm{y}$ hasta contradictoria puede ser- y que, en todo caso, nunca está ni de-terminada, ni de-finida. Pero tengamos cuidado aquí: más que para conocerse y conocer nuestra vida (cosa, el conocimiento, imposible), viajar es preciso simplemente para llegar a ser humano. Por ello el cosmopolitismo es una asunción antropológica antes que política: no podemos concebirnos si no es yendo de un sitio a otro, estando por todas partes, habitando el cosmos (sin que este tenga que ser ordenado y cabal como tampoco lo tendrá que ser nuestra propia vida). Sólo somos -aprendemos con Fougeret de Monbron, que muere justo cuando queda confinado a no moverse de su pueblo natal- cuando somos y estamos en muchos sitios porque nos vamos haciendo (que no conociendo) a través -atravesados- de todos esos sitios.

Quizás este sea el motivo por el que la ciudadanía del cosmopolita cínico se cuente en un libro de viajes que no es ni un libro de viajes, ni una autobiografía, ni siquiera un relato de ficción ${ }^{21}$. De hecho en alguna ocasión se ha destacado el modo en como Fougeret erradica la ficción 22 o el hecho de que en su obra no hay narración, que es una no-novela (Angeli 1974, p. 127) porque todo es una serie de sucesos puestos unos detrás de otro sin desear unificarlos en absoluto, sin pretender hacer un relato ni una historia; sólo hay pastiche y parodias unas detrás de otra sin que el orden signifique otra cosa que unas vienen detrás de otras: ni siquiera conforman una experiencia, sino que simplemente son un cúmulo de experiencias puestas al vuelo y según el azar y el juego del recuerdo y el olvido han dispuesto. Se ha apuntado que realmente lo que hace nuestro autor es huir de todo y de todos, no querer tener nada que ver con nadie, pero desde mi punto de vista y puesto que estoy convencido de que más que misántropo Monbron es un ateo social, no puedo estar

\footnotetext{
21 Es un lugar común la siguiente afirmación: “¿qué era entonces esta obrita [...]: autobiografía, retrato del autor por sí mismo, relato de viajes, compendio de historias galantes, panfleto político y literario?" (Trousson, 1971, p. 13).

22 "La verdadera desconfianza en relación a la ficción se expresa [...] inaugurando un principio que conservará en toda su obra; es en la composición misma, en el tejido del texto que Fougeret erradica la ficción" (Michel 2003, p. 67. Cfr. también p. 69).
} 
de acuerdo con esta afirmación (por otro lado bastante común). No es huida; el viaje de Fougeret de Monbron es una construcción constante de sí mismo que no cesa jamás de modificarse, "viajar es, pues, alejarse de la necesidad de ser fiel a un aquí y ahora y a un sí mismo. Viajar, y contarlo, es ser otro, componerse una identidad de jornada en jornada" (Michel 2000, p. 182) que ciertamente no se puede contar para siempre, una identidad que tan sólo es un relato tan casual como sin sustancia ni importancia, una identidad contradictoria y tan ficticia como una máscara o un disfraz ${ }^{23}$, pero, al cabo, todo lo que de nosotros podemos contar.

$\mathrm{Y}$ eso en definitiva aprendemos de El cosmopolita: todo es tan falso, tan fabricado, tan ficticio como risible: no debemos creer en nada, ni siquiera debemos creer en nosotros mismos que somos, como Fougeret de Monbron, tan dignos de risa y parodia que no sino el cuidado del comercio con los demás (lo más alejado de la misantropía) podemos promover para dar algún sentido a nuestro viaje que, al cabo, es el lugar donde aparecemos. Eso sí, aparecemos ahí pero nunca de un modo completo o "auténtico", sino simplemente como una secuencia no unificada de sucesos que se relatan entrelazados con el azar; realmente el viaje únicamente sirve para viajar y no para construirnos o hacernos mejores o más acordes a nuestra naturaleza: "después de haber visto mucho, me encuentro un poco menos tonto sin haberme hecho mejor" (Fougeret de Monbron 1750, p. 33).

\section{De la Antropología a la Política}

Quiero terminar con una última afirmación: Fougeret de Monbron, aun recalando en la orilla exclusiva de lo que podríamos llamar "el cultivo de sí", no deja de suponer un mundo social y político donde ese "sí" se puede establecer. Para mostrar esta afirmación creo que simplemente valdría advertir algo evidente en El cosmopolita, a saber, el hecho de que el viaje de Monbron no era un viaje que se hiciera pretrechado con una Guía de Viajes; por el contrario, habiéndolas leído todas suponía siempre que se estaba abierto a lo nunca imaginado, a lo que jamás antes se nos había ocurrido pensar. Esto es importante pues es reconocer que nos formamos siempre (y con ello adquirimos una forma), pero que aquello que somos no es esa forma, sino el hecho de que nos formamos. Ahora bien, formarse es adquirir una forma. Para no ser innecesariamente metafísico dígase aquí que Fougeret de Monbron sabe quien es Fougeret de Monbron cuando viaja, cuando navega, cuando entabla conversaciones y cuando se entera de historias y costumbres, pero real-

\footnotetext{
23 "Venecia es, sin duda, el lugar del mundo donde se puede sacar provecho de la vida del modo más agradable. Una de las grandes comodidades de este delicioso retiro y que apruebo con mucho aunque no sea de habitual un guarro, es la de poder defraudar con decencia los derechos de la lavandera y del barbero a favor de la máscara y la capa" (Fougeret de Monbron 1750, p. 89).
} 
mente se va dando cuerpo en la sedimentación que todas esas historias, acontecidos y curiosidades aglomeran en la orilla de su persona.

Nunca estamos, aprendemos en El cosmopolita, enteramente construidos y aunque es nuestra vida la que cuidamos y protegemos, esta se hace justamente en el cambio o al menos en la atención a -y deseo de cuidar de- lo diferente (de lo que no somos $-\mathrm{o}$ de lo que todavía no somos- nosotros). Necesitamos imaginar cosas distintas a nosotros mismos siquiera para imaginarnos a nosotros mismos. Este es el fundamento de un cosmopolitismo que se fundamenta en la consideración a lo diferente como punto fundamental desde el que construir la identidad. Es esta atención a la diferencia la que generalmente se olvida cuando se considera que no hay realmente diferentes, sino que todos somos humanos con una misma naturaleza e idénticos derechos (lo cual es la base sobre la que solemos edificar nuestro cosmopolitismo contemporáneo que, por el momento, se especifica en un mundo globalizado donde la diferencia tiene poca cabida si no es como diversidad de un fondo homogeneizado).

El cosmopolita no es sólo quien considera que en esencia o por naturaleza todos los seres humanos somos iguales, tampoco es quien con buen talante afirma que no hace falta tener grandes acuerdos para poder vivir unos con otros y por ello Cosmópolis se puede construir si no se es muy exigente (Appiah 2007), es, por el contrario, quien creyendo tal cosa da un paso más y se reconoce precisamente en la charla que entabla con aquellos que son como él y que no son como él. Y se reconoce no como alguien homogéneo, invariable, ya constituido, sino como alguien que es muy poca cosa, siempre ignorante, cuya propia identidad, cuyas afirmaciones, cuya vida, es simplemente una pluma lanzada al viento. Frágil, sin poder decir así soy yo siempre, pero, eso sí, reclamando el derecho -del curioso- a poder ir - constituirse- en cualquier dirección que el viento -el azar, la vida- le empuje. El cosmopolita cínico lo es porque es otro que él; o mejor: porque tiene lo otro dentro de él.

En cualquier caso el derecho del curioso es la reclamación del derecho a mirar y deambular, a charlar y negociar sin altivez, a saberse tan risible y pequeño como todos, a sólo desear viajar por el mundo no para mostrar un talante comprensivo ante lo diferente (que al final nunca se concibe como "tan diferente"), sino para sorprenderme aprendiendo donde estoy siendo. En este sentido es obvio que el cosmopolitismo cínico nos enseña que cuando se sale de casa sin considerar que se tiene una casa, sino creyendo que realmente la casa es el continuo y azaroso viajar (no el mundo entero globalizado y uniformado que expande nuestro propio hogar, sino el viajar para ver cosas curiosas, diferentes, distintas maneras de plantear el lugar que podría ser nuestra casa), cuando esto ocurre, digo, Cosmópolis es tomada como un afinamiento moral, como una manera de pulirse personalmente más que como un mecanismo de resolución de conflictos internacionales. Esta es la apuesta del cos- 
mopolita cínico o del ateo social: una vez impugnada la idea de nación, de casa, ¿por qué no olvidar el concierto de las naciones y apostar por el mundo global del viajero? Esta es una apuesta que construye el mundo desde los viajes efectivos de sus habitantes antes que desde las condiciones de posibilidad de tales viajes.

Debemos aprender la pequeñez de nuestros Derechos pero, al mismo tiempo, la pequeñez de cualesquiera otros. Sólo así podremos cambiar y concebir nuestra propia vida (nuestro propio mundo) de un modo tan experimental como debería ser la vida de todo viajero. No, no hay casa más allá del continuo viajar y ello supone que la vida humana se forja cuando salimos y miramos, cuando procuramos estar con los demás que son tan diferentes como risibles y, por ello, tan importantes y valiosos que constituyen la esencia misma del viaje. Porque si nos movemos no es para mirar piedras, sino para entablar conversaciones, vivir con los demás, aprender de ellos. Y disfrutar u odiar su compañía. Por ello el cosmopolita cínico se vuelca en defender al otro, en proteger lo diferente; sólo así podrá construir su propia identidad. Es otro tipo de cosmopolitismo que quizás hoy nos pudiera servir de algo. Es la diferencia entre Fougeret de Monbron y nosotros, entre salir de casa para mirar y quedarse en el salón viendo libros de viajes que nos muestran que todo el mundo se puede contener en nuestra propia casa. Quién sabe si no nos vendría mal concebir, por ejemplo, nuestros Derechos Humanos como un proyecto de permanente viaje, escucha y atención. Y por supuesto de renovación, de cambio, de volver a pensar todo lo que nos compone; incluso volver a pensar, siempre en el viaje, nuestra carta de Derechos Humanos.

\section{Referencias bibliográficas}

Angeli, G. (1974): "Il Cosmopolita", Saggi e Richerche di Letteratura Francese, 13, pp.114-141.

AppiAH, K.A. (2007): Cosmopolitismo: la ética en un mundo de extraños, Madrid, Katz.

Broome, J.H. (1960a): "Fougeret de Monbron. A 'Candide' Probleme Reconsidered", The Modern Languages Review, LV, pp. 509-518.

Broome, J.H. (1960b): "Byron et Fougeret de Monbron", Revue de littérature comparée, 34, pp. 337-353.

BRoOME, J.H. (1963): "L'homme au coeur velu: the turbulent career of Fougeret de Monbron", Studies on Voltaire and the Eighteenth-Century, 23, pp. 179-213.

Delon, M. (1992): "Presentación" de Margot la Ravaudeuse, Cadeilham, Zulma

Diderot, D. (1951): "Satire sur les caracteres et les mots de caractère, de profesión, etc." en Oeuvres, París, La Pléiade (Gallimard).

Fougeret De Monbron, L.-Ch. (1750): Le cosmopolite ou le citoyen du monde, Londres. 
LANGiLle É., (2010): “Introducción” a Fougeret de Monbron, Le Cosmopolite ou le Citoyen du Monde, Modern Humanities Research Association Critical Texts.

Lettevall, R. (2008): "The idea of Kosmopolis: Two kinds of Cosmopolitanism" en R. Lettevall \& M. K. Linder (eds.), The Idea of Kosmopolis, Södertörns Academia Studies 37, Hudinge (Suecia).

MiCHEL, L. (2000): "La polygraphie dans Le Cosmopolita ou le Citoyen du Monde de Fougeret de Monbron" en A. Chamayour (ed.), Éloge de l'adresse, Cahiers Scientifiques de l'Univesité d'Artois, 2000, pp. 171-188.

Michel, L. (2003): “Le libertin malgré lui. Une lectura de l'oeuvre de Fougeret de Monbron", Revue des Sciences Humaines, no 271, Julio-Septiembre, pp. 55-77

Morize, A. (1913): “Le 'Candide' de Voltaire”, Revue de XVIIIe. Siècle, 23, pp. 20-42.

Seonne, J. (2000): La política moral del Rococó, Madrid, Antonio Machado Libros.

Toulmin, S. (2001): Cosmópolis: el trasfondo de la Modernidad. Barcelona, Península.

Trousson, R. (1971): "Introducción" a Fougeret de Monbron, Le Cosmopolite, ou le citoyen du monde, suivi de La Capitale des Gaules ou la Nouvelle Babylone, Burdeos, Ducros.

Trousson, R. (1993): “Introducción” a Margot la Ravaudeuse en Romans libertins du XVIIIe siècle, París, Robert Laffont.

Venturi, F. (1947): “Fougeret de Monbron”, Belfagor, 2, pp. 170-186.

Julio Seoane Pinilla

Dpto. Historia I y Filosofía

Universidad de Alcalá de Henares

julio.seoane@uah.es 